\title{
Effect of dietary inclusion of high-oleic acid sunflower seed on the utilization of crude palm oil by broiler chickens*
}

\author{
C. Alzueta ${ }^{1}$, L.T. Ortiz, M.L. Rodríguez, A. Rebolé and J. Treviño \\ Department of Animal Production, Veterinary Faculty, \\ Complutense University, Ciudad Universitaria \\ 28040 Madrid, Spain
}

(Received 4 July 2006; revised version 20 December 2006; accepted 2 May 2007)

\begin{abstract}
Ground high-oleic acid sunflower seed (HOASS) was included into a basal diet containing $90 \mathrm{~g} \mathrm{~kg}^{-1}$ crude palm oil (PAO) to give levels of 0, 50, 100, 150 and $200 \mathrm{~g} \mathrm{~kg}^{-1}$, which resulted in PAO:HOASS fat ratios of 100:0, 75:25, 50:50, 25:75 and 0:100. The five diets were isonitrogenous and isoenergetic and were evaluated using broiler chickens from 3 to 6 weeks of age. Apparent digestibilities of dietary fat, palmitic, stearic and total fatty acids and AME of fat improved as the ratio of PAO:HOASS fat decreased, the observed response being curvilinear. A positive synergism between both fat sources was detected as demonstrated by the significantly greater determined values for the apparent digestibilities of crude fat, total fatty acids, palmitic acid, and AME of the dietary fat mixture than the theoretical values calculated from the values for the single components of fat mixture. The equation for estimating the energy value of dietary mixed fats showed that ascribing the same energy value to all fat mixtures should not be recommended for formulation of diets.
\end{abstract}

KEY WORDS: broilers, palm oil, high-oleic acid sunflower seed, fat, fatty acids, digestibility, metabolizable energy, synergism

\section{INTRODUCTION}

Animal and vegetable fats are commonly used in broiler diets to increase energy density and improve feed utilization efficiency. In the last few years,

\footnotetext{
* Supported by a Grant from CICYT (Comisión Interministerial de Ciencia y Tecnología) of Spain as a part of Project AGL2005-01759

${ }^{1}$ Corresponding author: e-mail: alzueta@vet.ucm.es
} 
full-fat oilseeds, that is, unextracted whole seeds, are being used to replace the supplemental fats added to broiler diets, avoiding well-known technical difficulties and quality problems related to the adding animal fat.

The use of hulled full-fat sunflower seeds, the hybrid oil varieties in particular, in animal feeding is of economic importance in some countries such as Spain because of their high energy content, moderate protein content (approximately $50 \%$ that of soyabean seed), and relatively moderate prices compared with other conventional nutrient sources. In the late 1980s, high-oleic acid cultivars of sunflower, having higher oxidative stability and better dietary properties than conventional genotypes, were developed (Katz, 1997). High-oleic acid sunflower seed is a source of monounsaturated fatty acids and, consequently, its inclusion in diets may increase the degree of unsaturation of intramuscular fat in broiler chickens without the negative effect on lipid oxidation associated with polyunsaturated fatty acids (Ortiz et al., 2006). In clinical studies, dietary monounsaturated fatty acids have been shown to be beneficial in lowering LDL-cholesterol but not HDLcholesterol concentrations in blood plasma, which reduces the risk of coronary heart disease (Roche, 2001).

It has been established that the intestinal absorption of fatty acids may vary largely because of the interactions between different fats added to diet. Thus, the nutritive value of a saturated fatty acid, defined in terms of the quantity of absorbed fat, may be improved in the presence of unsaturated fatty acids (Wiseman and Lessire, 1987; Doreu and Chilliard, 1997). Studies on the utilization of single fatty acids in poultry are thus of practical importance. The aim of current work was: 1. to assess the synergistic relationship between crude palm oil (PAO) and fat in high-oleic acid sunflower seed, evaluated in terms of apparent total tract digestibility (ATTD) of dietary crude fat, total and single fatty acids and of apparent metabolizable energy (AME) of crude fat, and 2. to determine the evolution of these nutritive parameters as a function of the crude PAO:HOASS fat ratio.

\section{MATERIAL AND METHODS}

\section{Materials}

A batch of HOASS (cv. Saxo), free of impurities, was obtained from a commercial supplier (Koipesol Semillas SA, Carmona, Sevilla, Spain) and used in the experiment. Commercially available crude PAO was provided by a supplier of feed-grade fats (Lípidos Santiga, SA, Santa Perpetua Modoga, Barcelona). The analytical composition of both materials appears in Table 1. 
Table 1. Composition of high-oleic acid sunflower seed (HOASS) and crude palm oil (PAO)

\begin{tabular}{lcc}
\hline Item & HOASS & Crude PAO \\
\hline Proximate analysis, $\mathrm{g} \mathrm{kg}^{-1} \mathrm{DM}$ & & \\
crude protein & 187.7 & \\
crude fat & 459.9 & \\
crude fibre & 130.4 & \\
neutral detergent fibre & 220.0 & \\
acid detergent fibre & 155.9 & \\
acid detergent lignin & 45.8 & \\
ash & 31.3 & \\
& & \\
Major fatty acids, $\mathrm{g} \mathrm{kg}^{-1}$ total fatty acids & & \\
C14:0 & $\mathrm{nd}$ & \\
C16:0 & 44.2 & 454.0 \\
C18:0 & 51.3 & 42.0 \\
C18:1n-9 & 807.2 & 388.7 \\
C18:2n-6 & 72.0 & 97.5 \\
others & 25.3 & 8.0 \\
U:S ${ }^{2}$ ratio & 7.80 & 0.96 \\
\hline
\end{tabular}

${ }^{1}$ nd - not detected; ${ }^{2} \mathrm{U}: \mathrm{S}$ - unsaturated: saturated

\section{Experimental procedures}

In the experiment carried out in the current study, birds were handled according to the principles of experimental procedures approved by the Complutense University Animal Care and Use Committee (Madrid, Spain).

Day-old-male broiler chicks (Cobb strain) obtained from a local hatchery were housed in electrically heated battery cages and fed on a commercial broiler starter diet until the beginning of the experiment. On day 22, a total of 175 chickens were weighed, moved to grower-finisher batteries, and allocated into 35 pens; each pen contained 5 birds and was assigned at random to one of the 7 replicates for each of the 5 dietary treatments. Feed and water were provided ad libitum.

The five dietary treatments consisted of a maize-soyabean meal basal diet containing $90 \mathrm{~g} \cdot \mathrm{kg}^{-1}$ crude PAO and four diets prepared incorporating 50, 100, 150 and $200 \mathrm{~g} \cdot \mathrm{kg}^{-1}$ ground HOASS into the basal diet (crude PAO:HOASS fat ratios of 100:0, 75:25, 50:50, 25:75 and 0:100, respectively); appropriate adjustments were made in the levels of ingredients so that a relatively constant crude fat concentration was maintained (Table 2). The diets were formulated according to the National Research Council (1994). Titanium dioxide was added to each diet at the rate of $5.0 \mathrm{~g} \mathrm{~kg}^{-1}$ in order to calculate the ATTD of crude fat and total and single fatty acids. The experimental diets were provided ad libitum from 22 to 42 days of age, and during the last three days excreta samples from each pen were collected 
daily and stored at $-20^{\circ} \mathrm{C}$. After being thawed, excreta were homogenized, freezedried and ground to pass a $1 \mathrm{~mm}$ sieve.

Table 2. Composition of experimental diets, $\mathrm{g} \mathrm{kg}^{-1} \cdot$ diet

\begin{tabular}{|c|c|c|c|c|c|}
\hline \multirow{2}{*}{ Item } & \multicolumn{5}{|c|}{$\mathrm{PAO}^{1}$ : fat in $\mathrm{HOASS}^{2}$ ratio } \\
\hline & 100:0 & $75: 25$ & $50: 50$ & $25: 75$ & $0: 100$ \\
\hline \multicolumn{6}{|l|}{ Ingredients } \\
\hline ground maize ${ }^{3}$ & 560 & 556 & 553 & 550 & 546 \\
\hline soyabean meal $(47.5 \mathrm{CP})$ & 270 & 240 & 210 & 180 & 150 \\
\hline soyabean protein isolate & 34 & 40 & 46 & 52 & 58 \\
\hline ground HOASS & - & 50 & 100 & 150 & 200 \\
\hline crude PAO & 90 & 68 & 45 & 22 & - \\
\hline DL-methionine & 3 & 3 & 3 & 3 & 3 \\
\hline sodium chloride & 3 & 3 & 3 & 3 & 3 \\
\hline dicalcium phosphate & 20 & 20 & 20 & 20 & 20 \\
\hline calcium carbonate & 9 & 9 & 9 & 9 & 9 \\
\hline titanium dioxide & 5 & 5 & 5 & 5 & 5 \\
\hline antioxidant (BHT) & 1 & 1 & 1 & 1 & 1 \\
\hline premix $^{4}$ & 5 & 5 & 5 & 5 & 5 \\
\hline \multicolumn{6}{|l|}{ Chemical composition } \\
\hline crude protein ${ }^{5}$ & 204 & 203 & 202 & 205 & 204 \\
\hline crude fat ${ }^{5}$ & 116 & 118 & 110 & 117 & 120 \\
\hline \multicolumn{6}{|c|}{ Major fatty acids, $\mathrm{g} \cdot \mathrm{kg}^{-1}$ total fatty acids ${ }^{3}$} \\
\hline $\mathrm{C} 16: 0$ & 342 & 276 & 201 & 122 & 67 \\
\hline $\mathrm{C} 18: 0$ & 43 & 44 & 42 & 42 & 41 \\
\hline $\mathrm{C} 18: 1 \mathrm{n}-9$ & 390 & 466 & 540 & 640 & 693 \\
\hline C18:2n-6 & 202 & 191 & 189 & 173 & 171 \\
\hline $\mathrm{U}: \mathrm{S}^{6}$ ratio & 1.53 & 2.01 & 3.06 & 4.95 & 7.13 \\
\hline AMEn, $M J ~ k g-1 \operatorname{diet}^{7}$ & 13.39 & 13.39 & 13.39 & 13.39 & 13.39 \\
\hline
\end{tabular}

${ }_{1}^{1}$ palm oil; ${ }^{2}$ high-oleic acid sunflower seed; ${ }^{3}$ maize containing $32.6 \mathrm{~g}$ crude fat $\mathrm{kg}^{-1} ;{ }^{4}$ premix supplying (mg. $\mathrm{kg}^{-1}$ diet) the following: 3 retinol, 55 cholecalciferol, $25 d l$ - $\alpha$-tocopheryl acetate, 2.5 menadione, 3 thiamine, 6 riboflavin, 7 pyridoxine, 0.2 folic acid, 0.02 cyanocobalamin, 0.2 biotin, 25 calcium pantothenate, 50 niacin, 1300 choline chloride, $29.5 \mathrm{CuSO}_{4} .5 \mathrm{H}_{2} \mathrm{O}, 375.0$ $\mathrm{FeSO}_{4} \cdot 7 \mathrm{H}_{2} \mathrm{O}, 138.0 \mathrm{ZnSO}_{4} \cdot \mathrm{H}_{2} \mathrm{O}, 277.0 \mathrm{MnSO}_{4} \cdot \mathrm{H}_{2} \mathrm{O}, 0.35 \mathrm{Na}_{2} \mathrm{SeO}_{3}, 0.20 \mathrm{KI}, 2.1 \mathrm{CoCl}_{2} \cdot 6 \mathrm{H}_{2} \mathrm{O}, 0.50$ $\mathrm{Na}_{2} \mathrm{MoO}_{4} \cdot 2 \mathrm{H}_{2} \mathrm{O} ;{ }^{5}$ analysed values ${ }^{6} \mathrm{U}: \mathrm{S}$ - unsaturated: saturated; ${ }^{7}$ calculated values

\section{Chemical analysis}

Dry matter, crude protein, crude fibre and ash were analysed following the standard methods of AOAC (Methods 930.15, 954.01, 978.10 and 942.05, respectively; 1995). Neutral detergent fibre, acid detergent fibre and acid detergent 
lignin were determined as described by Robertson and Van Soest (1981). Crude fat was determined by extraction with petroleum ether following acidification with 4N HCl to liberate saponified fatty acids (Wiseman et al., 1992).

Fatty acids from the crude fat extracts were methylated with a mixture of boron-trifluoride, hexane and methanol as described by Morrison and Smith (1964). The fatty acid methyl esters were analysed using a Chrompack CP-9001 gas chromatograph (Chrompack Instrumental BV, Middelburg, The Netherlands) equipped with a WCOT fused silica capillary column (length, $30 \mathrm{~m}$; ID, $0.32 \mathrm{~mm}$; film thickness, $0.50 \mu \mathrm{m}$ ), and flame ionization detector. Analyses were performed with a temperature programme from 170 to $250^{\circ} \mathrm{C}$ at a rate of $3.5^{\circ} \mathrm{C} \mathrm{min}$. Both injector and detector were maintained at $250^{\circ} \mathrm{C}$. The carrier gas was nitrogen at a flow rate of $4.5 \mathrm{ml} \mathrm{min}^{-1}$. Pentadecanoic acid (Sigma Chemical SA, Alcobendas, Spain) was used as the internal standard. Gross energy of extracted crude fat from diets was measured using an adiabatic bomb calorimeter (IKA Calorimeter $\mathrm{C}$ 4000-Janke and Kunkel GmbH \& Co, Staufen, Germany). Titanium dioxide was analysed colorimetrically according to the procedure of Short et al. (1996).

\section{Calculations and statistical analysis}

The AME content of crude fat in each diet was estimated as the product of its gross energy value and its ATTD value. The theoretical digestibility and AME content of dietary fat mixtures were calculated by multiplying the values determined for the diets containing only supplemental crude PAO or HOASS and their respective proportions in the diets including both fat sources.

Data were analysed using one-way ANOVA, and significant differences among means determined by Duncan's multiple range test. Data were also subjected to regression analysis by linear and quadratic models with the proportion of fat in HOASS in the crude PAO:HOASS fat mixture as the independent variable. The statistical analyses were performed by using the GLM procedures of SAS (1990).

\section{RESULTS}

The composition of HOASS and crude PAO used in the current study is detailed in Table 1. Analysis of the HOASS sample showed a crude fat content of $459.9 \mathrm{~g} \cdot \mathrm{kg}^{-1} \mathrm{DM}$ and, as expected, oleic acid was the major fatty acid, accounting for about $80 \%$ of the total fatty acids. The crude PAO sample contained high concentrations of palmitic and oleic acids, both fatty acids together contributing more than $84 \%$ to the total fatty acids.

Apparent digestibility data are presented in Table 3. A very low digestibility value was observed for stearic acid (0.266) in crude PAO. Analysis of variance 
revealed that the ATTD of dietary crude fat, palmitic, stearic and total fatty acids improved as the crude PAO:HOASS fat ratio decreased. The increments observed were markedly more pronounced for stearic acid (between 128 and 64\%) than for palmitic acid (between 66 and 32\%). The ATTD coefficients for unsaturated fatty acids (oleic and linoleic acids) were unaffected by the dietary treatments.

Table 3. Total tract apparent digestibility coefficients of crude fat, single fatty acids and total fatty acids and AME of crude fat in experimental diets

\begin{tabular}{|c|c|c|c|c|c|c|c|}
\hline & \multicolumn{7}{|c|}{$\mathrm{PAO}^{1}$ :fat in $\mathrm{HOASS}^{2}$ ratio } \\
\hline & 100:0 & $75: 25$ & $50: 50$ & $25: 75$ & $0: 100$ & SEM $^{3}$ & $P$ value \\
\hline \multicolumn{8}{|l|}{ Crude fat } \\
\hline determined digestibility & $0.630^{\mathrm{d}}$ & $0.729^{c}$ & $0.750^{\mathrm{bc}}$ & $0.786^{\mathrm{a}}$ & $0.783^{\mathrm{ab}}$ & 0.0130 & $* * *$ \\
\hline theoretical digestibility & $\ldots$ & 0.668 & 0.707 & 0.745 & $\ldots$ & & \\
\hline difference & $\ldots$ & $0.061^{* *}$ & $0.043^{*}$ & $0.041^{* *}$ & $\ldots$ & & \\
\hline \multicolumn{8}{|l|}{ C16:0 } \\
\hline determined digestibility & $0.447^{\mathrm{c}}$ & $0.590^{\mathrm{b}}$ & $0.708^{\mathrm{a}}$ & $0.744^{\mathrm{a}}$ & $0.720^{\mathrm{a}}$ & 0.0175 & $* * *$ \\
\hline theoretical digestibility & $\ldots$ & 0.455 & 0.472 & 0.508 & $\ldots$ & & \\
\hline difference & $\ldots$ & $0.135^{* *}$ & $0.236^{* *}$ & $0.236^{* *}$ & $\ldots$ & & \\
\hline \multicolumn{8}{|l|}{ C18:0 } \\
\hline determined digestibility & $0.266^{\mathrm{e}}$ & $0.435^{\mathrm{d}}$ & $0.520^{\mathrm{c}}$ & $0.606^{\mathrm{b}}$ & $0.705^{\mathrm{a}}$ & 0.0238 & $* * *$ \\
\hline theoretical digestibility & $\ldots$ & 0.393 & 0.508 & 0.612 & $\ldots$ & & \\
\hline difference & $\ldots$ & 0.042 & 0.012 & -0.006 & $\ldots$ & & \\
\hline$C 18: \ln -9$ & 0.812 & 0.807 & 0.811 & 0.800 & 0.826 & 0.0146 & Ns \\
\hline$C 18: 2 n-6$ & 0.732 & 0.744 & 0.776 & 0.746 & 0.787 & 0.0143 & Ns \\
\hline \multicolumn{8}{|l|}{ Total fatty acids } \\
\hline determined digestibility & $0.654^{\mathrm{d}}$ & $0.739^{\mathrm{c}}$ & $0.764^{\mathrm{bc}}$ & $0.791^{\mathrm{ab}}$ & $0.815^{\mathrm{a}}$ & 0.0110 & *** \\
\hline theoretical digestibility & $\ldots$ & 0.695 & 0.735 & 0.775 & $\ldots$ & & \\
\hline difference & $\ldots$ & $0.044^{*}$ & $0.029^{*}$ & 0.016 & $\ldots$ & & \\
\hline \multicolumn{8}{|l|}{ AME of crude fat, $M J \mathrm{~kg}^{-1}$} \\
\hline determined digestibility & $24.8^{\mathrm{c}}$ & $28.8^{\mathrm{b}}$ & $29.6^{\mathrm{b}}$ & $31.0^{\mathrm{a}}$ & $30.9^{\mathrm{a}}$ & 0.38 & $* * *$ \\
\hline theoretical digestibility & $\ldots$ & 26.3 & 27.9 & 29.4 & $\ldots$ & & \\
\hline difference & $\ldots$ & $2.5^{* *}$ & $1.7^{*}$ & $1.6^{* *}$ & $\ldots$ & & \\
\hline
\end{tabular}

The AME content of dietary crude fat is also given in Table 3. The results of ANOVA indicated that, similarly as with the digestibility coefficients, the positive changes in the AME content of crude fat attributable to the inclusion of HOASS in the basal diet were highly significant $(\mathrm{P}<0.001)$. The AME value increased from 
24.8 (basal diet without HOASS) to $31.0 \mathrm{MJ} \mathrm{kg}^{-1}$ (diet with a crude PAO:HOASS fat ratio of 25:75).

The determined digestibilities and AME content of dietary fat mixtures were compared with theoretical values and the significance of the differences was measured by a $t$-test (Table 3 ). The determined ATTD coefficients for crude fat, palmitic acid, total fatty acids (except in the diet with a ratio of 25.75), and for AME of crude fat were significantly greater $(\mathrm{P}<0.05)$ than the corresponding theoretical values. The magnitude of the differences between theoretical and determined values did not vary significantly $(\mathrm{P}>0.05)$ in the case of stearic acid.

Regression analysis, using linear and quadratic models, was carried out to assess the evolution of the apparent digestibility variables and AME content of dietary crude fat as a function of the proportion of fat in HOASS in the crude PAO:HOASS fat mixture. The results, presented graphically in Figure1, showed that the effect of increasing the proportion of fat in HOASS in the fat mixture on the apparent digestibility of dietary crude fat, palmitic, stearic and total fatty acids, and AME content was significantly linear and quadratic $(\mathrm{P}<0.001)$. However, with only the exception of stearic acid, the quadratic model described the relationship between variables better than the linear model, as deduced by the respective $\mathrm{r}^{2}$ value. This indicated a curvilinear effect in the response of some of the nutritive variables examined to the inclusion of HOASS in the basal diet.

\section{DISCUSSION}

The results of the current study demonstrated that feeding crude PAO in conjunction with HOASS improved the utilization of the dietary fat mixture, as deduced from the increase in both its apparent digestibility and its AME content. This seems to be a logical consequence from the higher digestibility of palmitic and stearic acids in HOASS than in crude PAO and the similar extent to which the unsaturated fatty acids in both ingredients were digested. However, when the determined and theoretical changes associated with the gradual substitution of fat in HOASS for crude PAO in the fat mixture were compared, it was found that the ATTD coefficients for crude fat and palmitic and the AME value of dietary crude fat were significantly greater than the theoretical values at crude PAO:HOASS fat ratios of 75:25, 50:50 and 25:75, which indicated that there was a synergetic interaction between both fats. The average increase attributable to synergism was $6.9,42.3$ and $7.0 \%$ for the ATTD of crude fat and palmitic acid and for the AME content of dietary fat, respectively. Such an effect presumably reflects the ability of oleic acid, about $80 \%$ of the total fatty acids in fat in HOASS, to interact in a positive way with palmitic acid, which accounts for approximately $50 \%$ of the total fatty acids in crude PAO. Regarding this, it is also possible that 
an interaction between vegetable oils and some ingredients of the basal diet, for example maize, might also have improved the absorption of saturated fatty acids in crude PAO. However, in the current experiment, the amount of vegetable fat in the basal diet provided by the ingredients, excluding crude PAO, was very low and rather constant (about $21.2 \mathrm{~g} \cdot \mathrm{kg}^{-1}$ ) and, therefore, it was assumed that the changes observed in the dietary fat fraction were due to the inclusion of HOASS.

In general, these findings are in accordance with those reported by other researchers, who observed synergetic interactions between the saturated fatty acids of supplemental animal fats and the unsaturated fatty acids of vegetable oils. Thus, Wiseman and Lessire (1987) indicated that the availability of both palmitic and stearic acids was relatively low for pure tallow when fed to chickens and cockerels, but increased gradually as the proportion of rape oil in the fat mixture was raised. Ketels and De Groote (1989) showed that mixing soyabean oil with beef tallow or lard led to increased saturated fatty acid utilization, whereas utilization of unsaturated fatty acids was not affected. The mechanism responsible for synergism between fats is the capacity of polar solutes (for example, unsaturated fatty acids) to increase the micellar solubility of non-polar solutes, such as longchain saturated fatty acids (Freeman, 1984). Varying degrees of synergism between fats have been described and attempts to quantify fatty acid interactions have been carried out in order to estimate the relative concentration of unsaturated:saturated fatty acids needed to promote maximum synergism in terms of apparent fatty acid digestibility and metabolizable energy value. Thus, unsaturated-to-saturated fatty acid ratios of 3.4:1-2.2:1 (Fuller and Dale, 1982) and 2.0:1 (Dänicke et al., 2000) have been suggested. In the current study, using crude PAO and HOASS as supplemental energy sources, the maximum synergism in the digestibility and AME content of dietary mixed fats was observed at an unsaturated: saturated fatty acid ratio of 2.0:1 (diet with a crude PAO:HOASS fat ratio of 75:25).

The digestibility of unsaturated fatty acids in the experimental diets was not affected $(\mathrm{P}>0.05)$ by the crude PAO:HOASS fat ratio. Digestibility values for oleic acid were rather similar in all dietary treatments, whereas values for linoleic acid showed an appreciable but non-significant $(\mathrm{P}=0.056)$ variability. The latter may be attributable to the low concentration of linoleic acid in the diets. Wiseman and Lessire (1987) reported that the utilization of oleic and linoleic acids by adult birds did not appear to be influenced by the composition of tallow and rape oil mixtures.

The results of regression analysis indicated that there was a departure from linearity in the response of the ATTD of crude fat, palmitic and total fatty acids, and also in the AME content of crude fat to increasing the proportion of fat in HOASS in the dietary fat mixture. Synergetic interaction between both fats, mainly between palmitic and oleic acids, would explain to a large extent of the curvilinear effect caused by the inclusion of HOASS. Applying the equations derived from 

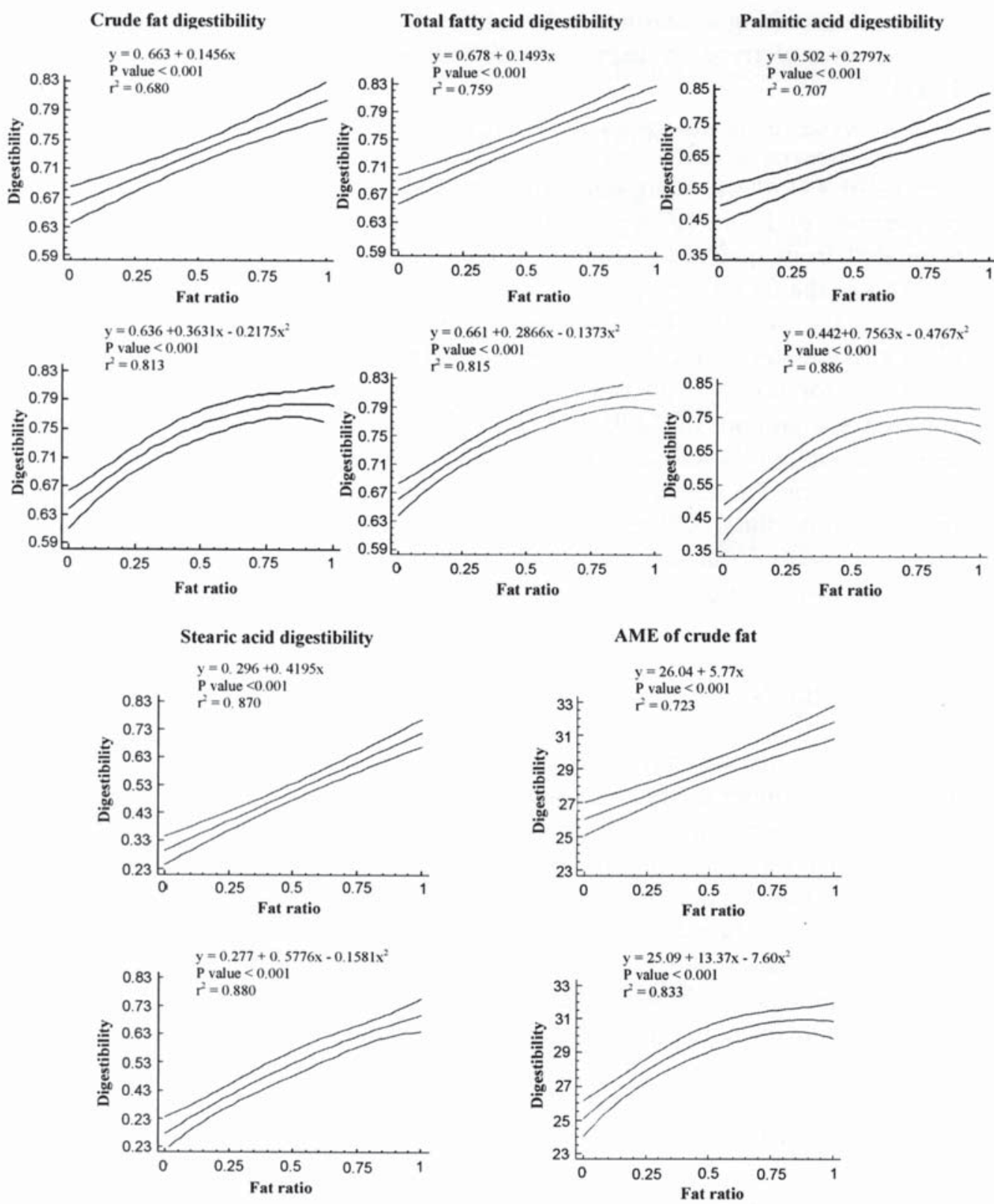

Figure 1. Regression analysis (linear, $y=a+b x$; quadratic, $y=a+b x+c x^{2}$ ) relating digestibility coefficients of crude fat, total fatty acids, palmitic and stearic acids and AME content (MJ $\left.\mathrm{kg}^{-1}\right)$ of crude fat $(y)$ to proportion of fat in HOASS $(x)$ in the crude PAO:fat in HOASS mixture in experimental diets (dotted lines denote $95 \%$ confidence interval). $\mathrm{PAO}=$ palm oil; HOASS $=$ higholeic acid sunflower seed 
fitting variables to a quadratic model (Figure 1), ATTD coefficients for dietary fat and its AME content at a given proportion of substitution of fat in HOASS for crude PAO were estimated. Moreover, an equation describing a marginal value of the AME content of dietary fat, in steps of $1 \%$, was derived by using the following general formula (Ketels et al., 1987):

$$
\mathrm{M}(\mathrm{x})=\mathrm{x} * \mathrm{~F}(\mathrm{x})-(\mathrm{x}-1) * \mathrm{~F}(\mathrm{x}-1)
$$

where, $M(x)=$ the marginal value of AME of dietary crude fat, $x=$ the proportion of fat in HOASS in the fat mixture, and $\mathrm{F}(\mathrm{x})=$ the AME value estimated from quadratic equation (Figure 1) at the $\mathrm{x}$-th proportion of fat in HOASS in the fat mixture.

Thus, for example, by using this formula, the marginal energy values for dietary crude fat $\left(90 \mathrm{~g} \cdot \mathrm{kg}^{-1}\right)$ were estimated at substitution levels of fat in HOASS for crude PAO ranging from 10 to $90 \%$. Estimated values varied between a minimum of $24.96 \mathrm{MJ} \mathrm{kg}^{-1}$ (90\% of substitution) to a maximum of $31.0 \mathrm{MJ} \mathrm{kg}^{-1}$ ( $45 \%$ of substitution). This suggests that precise and accurate information on the nutritive value of fats when they are mixed is very variable from the nutritional and economic points of view, and knowledge about the marginal energy value can prevent underestimation or overestimation of the true energy of mixed fats.

\section{CONCLUSIONS}

It is concluded that the seeds of high-oleic acid sunflower might be used in poultry diets containing fats rich in saturated fatty acids in order to improve their utilization. Significant improvement in the digestibility of saturated fatty acids was obtained by decreasing the PAO:HOASS fat ratio, which may be attributed to both the highest palmitic and stearic acid digestibilities in HOASS and the synergetic interaction found between unsaturated acids (mainly oleic acid) in HOASS and palmitic acid in PAO. The equation for estimating the energy value of dietary mixed fats showed that ascribing one energy value to fat mixtures may not be recommendable for use in formulation of diets.

\section{ACKNOWLEDGEMENTS}

The authors wish to thank KOIPE SA (Andújar, Jaén, Spain) for supplying the high-oleic acid sunflower seed used in this study. 


\section{REFERENCES}

AOAC, 1995. Official Methods of Analysis, Association of Official Analytical Chemists. $16^{\text {th }}$ Edition. Arlington, VA

Dänicke S., Jeroch H, Böttcher W., Simon O., 2000. Interaction between dietary fat type and enzyme supplementation in broiler diets with high pentosan contents: effects on precaecal and total tract digestibility of fatty acids, metabolizability of gross energy, digesta viscosity and weights of small intestine. Anim. Feed Sci. Tech. 84, 279-294

Doreu M., Chilliard Y., 1997. Digestion and metabolism of dietary fat in farm animals. Brit. J. Nutr. 78, Suppl. 1, S15-S35

Freeman C.P., 1984. The digestion, absorption and transport of fats - non-ruminants. In: J. Wiseman (Editor). Fats in Animal Nutrition. Butterworths, London, pp. 105-122

Fuller H.L., Dale N.M., 1982. Effect of ratio of basal diet fat to test fat on the true metabolisable energy of the test fat. Poultry Sci. 61, 914-918

Katz F., 1997. The move towards genetically improved oils. Food Technol. 51 (11), 66

Ketels E., De Groote G., 1989. Effect of ratio of unsaturated to saturated fatty acids of the dietary lipid fraction on utilization and metabolizable energy of added fats in young chicks. Poultry Sci. $68,1506-1512$

Ketels E., Huyghebaert G., De Groote G., 1987. The nutritional value of commercial fat blends in broiler diets. I. Effect of the incorporation level on the metabolizable energy content. Arch. Geflügelk. 51, 59-64

Morrison W.R., Smith M.L., 1964. Preparations of fatty acid methyl esters and dimethylacetals from lipid with boron fluoride methanol. J. Lipid Res. 5, 600-608

National Research Council, 1994. Nutrients Requirements of Poultry. National Academy Press. Washington, DC

Ortiz L.T., Alzueta C., Rebolé A., Rodríguez M.L., Brenes A., Arija I., 2006. Effect of dietary higholeic acid and conventional sunflower seeds and their refined oils on fatty acid composition of adipose tissue and meat in broiler chickens. J. Anim. Feed Sci. 15, 83-95

Robertson J.B., Van Soest P.J., 1981. The detergent system of analysis and its application in human foods. In: W.P.T., James O. Theander (Editors). The Analysis of Dietary Fiber in Food. New York, Marcel Dekker, pp. 123-158

Roche H.M., 2001. Olive oil, high-oleic sunflower oil and CDH. Brit. J. Nutr. 85, 3-4

SAS, 1990. SAS User's Guide: Statistics. SAS Institute Inc. Cary, NC

Short F.J., Gorton P., Wiseman J., Boorman N.K., 1996. Determination of titanium dioxide added as an inert marker in chicken digestibility studies. Anim. Feed Sci. Tech. 59, 215-221

Wiseman J., Edmunds B.K., Shepperson N., 1992. The apparent metabolizable energy of sunflower oil and sunflower acid oil for broiler chickens. Anim. Feed Sci. Tech. 36, 41-51

Wiseman J., Lessire M., 1987. Interactions between fats of different chemical content: apparent availability of fatty acids. Brit. Poultry Sci. 28, 677-691 